\title{
Sagittal plan deformiteleri ve tedavisi
}

\author{
Sagittal plane deformities and their treatment
}

\author{
Mehmet Halıcı
}

Erciyes Üniversitesi Tıp Fakültesi, Ortopedi ve Travmatoloji Anabilim Dalı, Kayseri

\begin{abstract}
Ekstremitelerin uygun dizilimi, efektif yük aktarımı ve mekanik kuvvetin verimli şekilde kullanılması için son derece önemlidir. Bu mekanik aktarım zincirinin çeşitli nedenlerle bozulduğu durumlarda hareket momentleri ve basınç noktaları değişerek uzun dönemde eklem üzerindeki optimum yük dağılımını bozup artrite sebep olmaktadır. Sagittal plandaki dizilim bozuklukları genellikle komşu eklemler tarafindan iyi kompanse edilir, ancak en yüksek enerji veriminin sağlanması için optimal dizilimin yeniden sağlanması gereklidir. Optimal sagittal dizi$\mathrm{lim}$, ekstremiteden elde edilen proprioseptif verinin yorumlanması sonucunda ilgili ligament ve tendonların gerilim kuwvetinin serebro-musküler kontrolü açısından önem taşımaktadır. Sagittal plan deformitelerinin belirlenmesi için uygun mekanik ve anatomik eksen ölçümleri yapılır. Bu ölçümler kompansasyon mekanizmaları göz önünde bulundurularak hem dinamik hem statik olarak değerlendirilmelidir. Alt ekstremite sagittal plan deformiteleri yürümenin mekanik fazları ile doğrudan ilişkilidir böylece hastanın ambulatuar durumu ile direkt olarak ilişkilidir. Bu yazının amacı, sagittal plan deformitelerinin tanısını, anatomi ve mekanik arasındaki ilişkiyi ve bu patolojiye sahip olguların yönetimini irdelemektedir.
\end{abstract}

Anahtar sözcülkler: sagittal plan deformitesi; deformite planlama; yumuşak doku girişimleri; cerrahi yaklaşım
Appropriate alignment of the extremity is crucial to maintain efficient use of force and proper load distribution on the joint surface. Disruption of regular alignment causes abnormal pressure zones on the joint surfaces and muscle, ligament and tendon imbalance which triggers the degradation of the cartilage and causing arthrosis in the long term. Sagittal plane deformities are mostly well-compensated by juxta-articular joints. However, efficient movement of the extremity is only possible with correctly aligned anatomic structures. Besides, anatomic alignment of the extremity is also associated with the proprioceptive sensation which is essential to regulate the tension of surrounding muscles, ligaments and tendons. Accurate radiographic measurements should be made to evaluate deformity. Both static and dynamic measurements should be carried out considering the compensation mechanisms. Sagittal plane deformities of the lower extremity directly associated walking and movement and therefore, the ambulatory status of the patient. The objective of this chapter is to explain the diagnosis, management and anatomic and mechanic relations of the sagittal plane deformities.

Key words: sagittal plane deformity; deformity planning; soft tissue procedures; surgical approaches

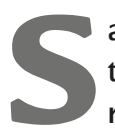
agittal plan deformiteleri frontal plan deformitelerine göre daha iyi tolere edilir ve klinik olarak daha az bulgu verir. Sagittal plandaki dizilim bozuklukları; kalça, diz, ayak bileği, subtalar ve orta ayak eklemleri tarafından telafi edilir. Sagittal plan deformiteleri ilerleyen süreçte semptomatik hale gelebilir ve geç dönemde dejenaratif artrit gelişebilir.

Distal tibia rekurvatum deformitelerinde, talusun kaplanması azalır ve geç dönemde dejeneratif değişiklikler görülür. Distal tibia prokurvatum deformitesi, tibiotalar eklemin anteriorunda sıkışmaya ve ağrıya yol açar. Proksimal tibial rekurvatum, sıklıkla patellar kondromalazi oluşumuyla birliktedir. Proksimal tibial prokurvatum ise; dizde fleksiyon deformitesi, kondromalazi patella ve ağrı ile birliktedir. Distal femoral prokurvatum deformitesi; posterior kapsülde gerilme ile birlikte, dizde fleksiyon deformitesi ve kondromalazi patella ile seyreder. Distal femoral rekurvatum deformitesi ise; dizde fleksiyon kaybı ile birliktedir. Proksimal femoral fleksiyon ve ekstansiyon deformiteleri nadiren semptomatik olup, lomber vertebralardan kompanse edilir. Kalçanın sabit fleksiyon deformiteleri; lomber hiperlordoz, sabit ekstansiyon deformiteleri ise; kalça fleksiyonunda azalma ile birliktedir. ${ }^{[1]}$

Diz tam ekstansiyonda iken sagittal planda alt ekstremitenin mekanik ekseni, femur başı orta noktası ile

- İletişim adresi: Prof. Dr. Mehmet Halıcı, Erciyes Üniversitesi Tıp Fakültesi, Ortopedi ve Travmatoloji Anabilim Dalı, Kayseri Tel: 0532 - 3961896 e-posta: dr.mhalici@gmail.com

- Geliș tarihi: 28 Kasım 2019 Kabul tarihi: 20 Ocak 2020 
ayak bileği ekleminin ortasından çizilen çizgi, diz ekleminin anteriorundan geçecek şekilde olup, bu dizilim diz ekleminin ekstansiyonda kilitlenmesine olanak sağlar. Alt ekstremitenin mekanik ekseni diz ekleminin pivot noktasından geçerse, diz eklemi $5^{\circ}$ fleksiyonda olur. ${ }^{[2]} \mathrm{Bu}$ durumda tek ayak adım atma sonrası, dizde son $5^{\circ}$ 'lik ekstansiyonda kısıtlılık oluşur. Dizde tam ekstansiyon veya hiperekstansiyon, paralitik durumlar dışında nadiren görülür. Hastalarda pasif olarak belirgin hiperekstansiyon görülmesine rağmen yürüyüş esnasında diz hiperekstansiyona gelmez. Bu durum serebrokortikal ve proprioseptif kontrolün, ligament ve kapsüller etkiden daha baskın olmasıyla gerçekleşir. Normal sagittal dizilim, femurun anteriorundan aşağıya doğru çizilen çizginin, proksimal tibianın anterior korteksinden devamı şeklinde olup, bu alt ekstremitenin uygun dizilimi olarak kabul edilir. ${ }^{[3]}$

Ameliyat öncesi; sagittal plan deformitelerinin değerlendirilmesinde anatomik eksen metodu kullanılabilir. Anatomik eksen metodunda; diafizin ortasından geçen çizgiler ile eklem oryantasyon çizgilerinin kesişim noktasında oluşan açısal ölçümler kullanılır. Tek taraflı deformitelerde, karşı ekstremite şablon olarak kullanılabilir. Ancak elde veri olmadığı durumlarda ortalama değerler kullanılabilir. ${ }^{[4]}$ Sagittal plan dizilim bozuklukları; femur ya da tibianın deformiteleri kaynaklı olabildiği gibi, diz eklemi kontraktür, laksite ya da subluksasyonları kaynaklı da olabilir. ${ }^{[5]}$

\section{Sagittal Plan Dizilim Bozukluğunun Değerlendirilmesi}

Alt ekstremitenin sagittal plandaki dizilim bozukluğu, frontal plana göre daha iyi tolere edilir. Frontal planda dizin hareket açıklığını tolere edecek bir mekanizma yok iken, sagittal planda diz hareketleri; kalça, diz, ayak bileği dizilimi ile normal diz hareketi ve yürüyüşten etkilenir. Bu yüzden statik olarak frontal dizilimi değerlendirmek yeterli olmasına karşın, sagittal planı mutlak dinamik faktörlerle birlikte değerlendirmek gereklidir.

Kalçanın rotasyon merkezinden başlayıp, femur başının orta noktasından ayak bileğinin rotasyon merkezine çizilen çizgi (lateral radyografide talusun lateral çıkıntısının tepesi) sagittal planda alt ekstremitenin mekanik eksenidir. Diz tam ekstansiyonda iken, alt ekstremitenin mekanik ekseni diz ekleminin rotasyon merkezinin anteriorundan geçer. Diz eklemi rotasyon merkezi, lateral radyografide femurun posterior korteksinden aşağıya doğru uzanan çizgi ile Blumensaat çizgisinin kesiştiği noktadır. Bu durumda diz eklemi tam ekstansiyonda kilitlenerek kuadriseps adelesinin gevşemesine yol açar. Sagittal planda mekanik eksen dizin rotasyon merkezinin anteriorundan geçmez ise; dizdeki deformite nedeniyle kuadriseps adelesi sürekli dizi ekstansiyonda tutmaya çalışır, bu durum kuadriseps adelesinin güçsüzlügüne neden olur. Mekanik ekseni daha öne taşımak paralitik hastalarda (poliomyelitis, spina bifida vb.) diz kilitlenmesini sağlamak için en önemli telafi mekanizmasıdır. Sagittal planda dizin rotasyon merkezi, diz eklemi $5^{\circ}-10^{\circ}$ fleksiyonda iken normalde aynı çizgi üzerinde yer alır (Şekil 1).

Normal yürüyüş esnasında diz ekstansiyonu $5^{\circ}$ den fazla olmaz. Bu kapsüloligamentöz yapının, terminal ekstansiyonu yürüyüş esnasında sınırlamasıyla olur. Hamstring adelelerinin kasılması, yürüyüş esnasında terminal ekstansiyonu sınırlar ve bu esnada hiperekstansiyon görülmez. Tibianın rekurvatum deformitesi, diz ekleminde fleksiyon kaybı ile kompanse edilirken, femurun fleksiyon deformitesi diz ekleminin hiperekstansiyonuna yol açar. Frontal plandaki dizilim bozuklukları dizin her bir kompartmanında yüklenmeye yol açar ancak sagittal planda yuvarlak şekli nedeniyle bir kompartmana frontal plandaki kadar yük binmez. Bu bakımdan erken osteoartritik lezyonlar, femurun posteriorundan daha çok anteriorunda görülür. Dizde maksimum yüklenme dizin $15^{\circ}-20^{\circ}$ fleksiyonunda olur.

Dizin sagittal plandaki dizilim bozukluğu frontal plana göre daha iyi tolere edilir. Bunun en önemli nedeni; kalça, diz ve ayak bileği eklemi tarafından telafi edilebilmesidir. Tibianın rekurvasyon deformitesi diz fleksiyon kontraktürü ile telafi edilirken, distal femurun fleksiyon deformitesi ise diz ekleminin hiperekstansiyonu ile telafi edilebilmektedir. Bu özellikle rekurvasyon deformiteleri için geçerli olup, prokurvasyon deformitelerinde ise daha sınırlıdır.

Sagittal plan dizilim bozukluğunun diğer bir nedeni ise diz ekleminin subluksasyonudur. Normal olarak diz tam ekstansiyonda iken, sagittal planda lateral femoral kondilin ortası ile tibianın orta sagittal noktası aynı düzlem üzerindedir. Femur ve tibianın sagittal planda orta noktalarından geçen çizginin, orta hattan $3 \mathrm{~mm}$ 'den fazla olması; anterior veya posterior diz subluksasyonudur.

Frontal plan dizilim bozukluğunun değerlendirilmesinde; lateral veya medial eksen sapması değerlendirmede kriter olarak alınmaktadır. Aynı şekilde sagittal planda dizilim bozukluğunun değerlendirilmesinde fleksiyon ve ekstansiyon deformitesinin varlığına bakılır. Sagittal planda fleksiyon dizilim bozukluğu var ise; alt ekstremitenin mekanik ekseni dizin rotasyon merkezinin posteriorundan geçerken, ekstansiyon dizilim bozukluğunda ise, mekanik eksen $5^{\circ}$ hiperekstansiyondadır (Şekil 2, 3).

Fleksiyon ve ekstansiyonda eklemdeki kompansatuvar hareket yüzünden, sagittal plan dizilim bozukluğunda yanlış ölçümler yapılabilir. Sagittal planda kemik 


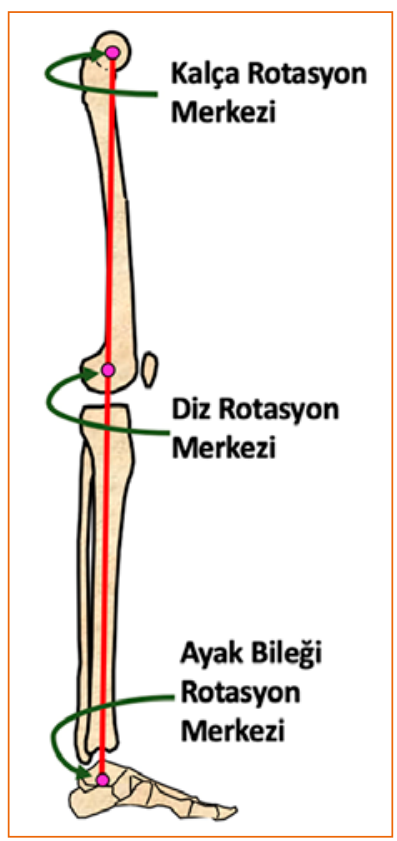

Şekil 1. Normalde kalça, diz ve ayak bileğinin rotasyon merkezleri, diz $5^{\circ}-10^{\circ}$ fleksiyonda iken aynı doğru üzerinde yer alır.

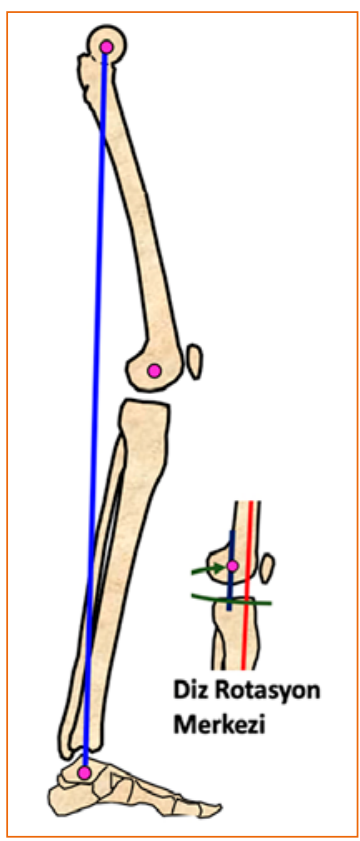

Şekil 2. Fleksiyon dizilim bozukluğu: Dizin maksimum ekstansiyonda çekilen radyografisinde sagittal plandaki mekanik eksen, dizin rotasyon merkezinin anteriorundan geçmiyorsa fleksiyon dizilim bozukluğu vardır.

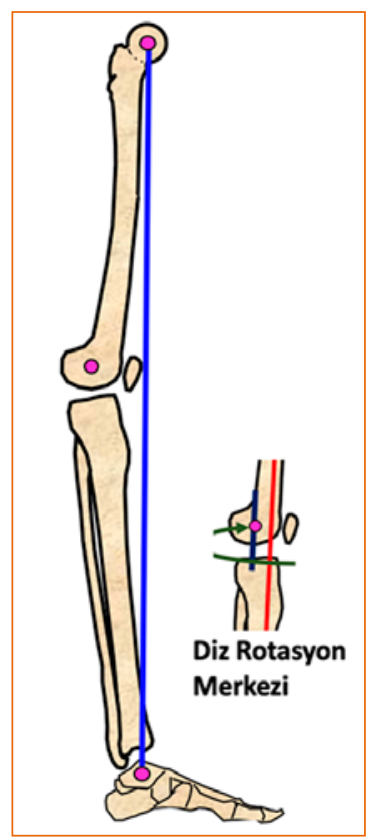

Şekil 3. Ekstansiyon dizilim bozukluğu: Sagittal planda diz pasif olarak $5^{\circ}$ 'den daha fazla ekstansiyona getirilebiliyorsa ekstansiyon dizilim bozukluğu vardır. (a)

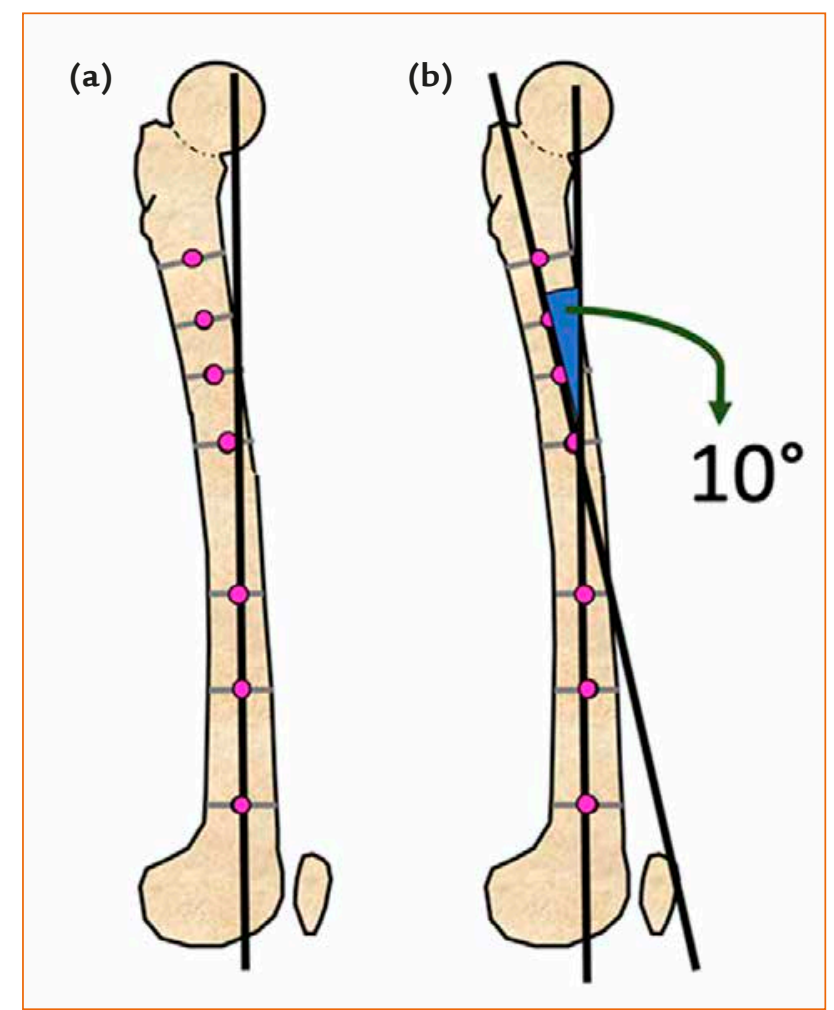

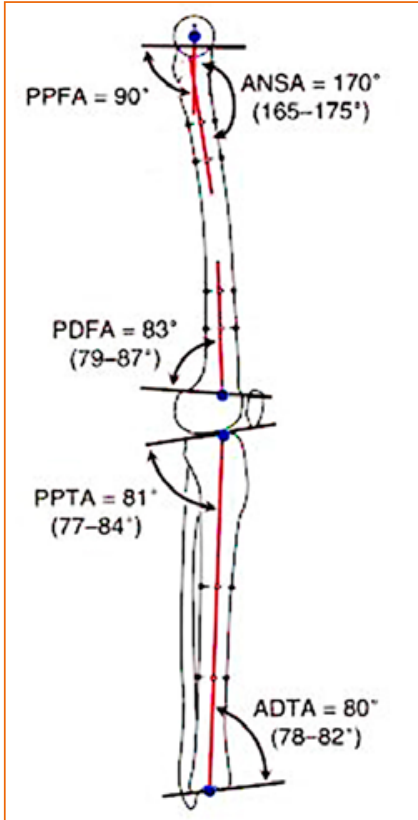

Şekil 4. Sagittal planda anatomik eksene göre eklem oryantasyonlarının normal değerleri. deformitelerinin değerlendirilmesinde; distal femur ve proksimal tibia eklem oryantasyonlarının değerlendirilmesi gereklidir. Tibianın sagittal planda normal olarak anatomik ekseninin; proksimalde tibial eklem çizgisinin 1/5 ön kısmıyla, distalde ise orta noktasından geçirilen çizgilerin eklem yüzeyi ile birleştirilmesiyle eklem oryantasyonları değerlendirilebilir. Proksimalde aPPTA (anatomik Proksimal Posterior Tibial Açı) $81^{\circ} \pm 4^{\circ}$ iken, distalde aADTA (anatomik Anterior Distal Tibial Açı) $80^{\circ} \pm 2^{\circ}$ 'dir. Normal olarak femur distal diafizinin orta noktasından geçen çizginin Blumensaat çizgisiyle kesiştiği noktanın posteriorundaki açı aPDFA (anatomik Posterior Distal Femoral Açı) olup, $83^{\circ} \pm 4^{\circ}$ 'dir. Proksimalde diafizin ortasından geçen çizgi ile femur boynu ortasından çizilen çizginin kesişim noktasının posteriorunda oluşan açı aPPFA (anatomik Posterior Proksimal Femoral Açı) $90^{\circ}$ 'dir. Femurun proksimalde diafizinin orta noktasından geçen çizgi ile epifiz hattı veya kapanma çizgisi arasında oluşan açı ANSA olup, normal değeri $170^{\circ} \pm 5^{\circ}$ 'dir (Şekil 4). Sagittal planda proksimal ve distal middiafizer çizgilerin kesişme noktası MDA (middiafizer açı) olup, $10^{\circ}$ 'dir (Şekil 5). Mekanik eksene göre, sagittal planda femur başı orta

Şekil 5. a, b. Femur sagittal planda düz değildir. Bu eğrilik nedeniyle, femurun proksimal ve distal yarısının anatomik ekseni ayrı çizilir. İkisi arasında normalde $10^{\circ}$ açı vardır. 


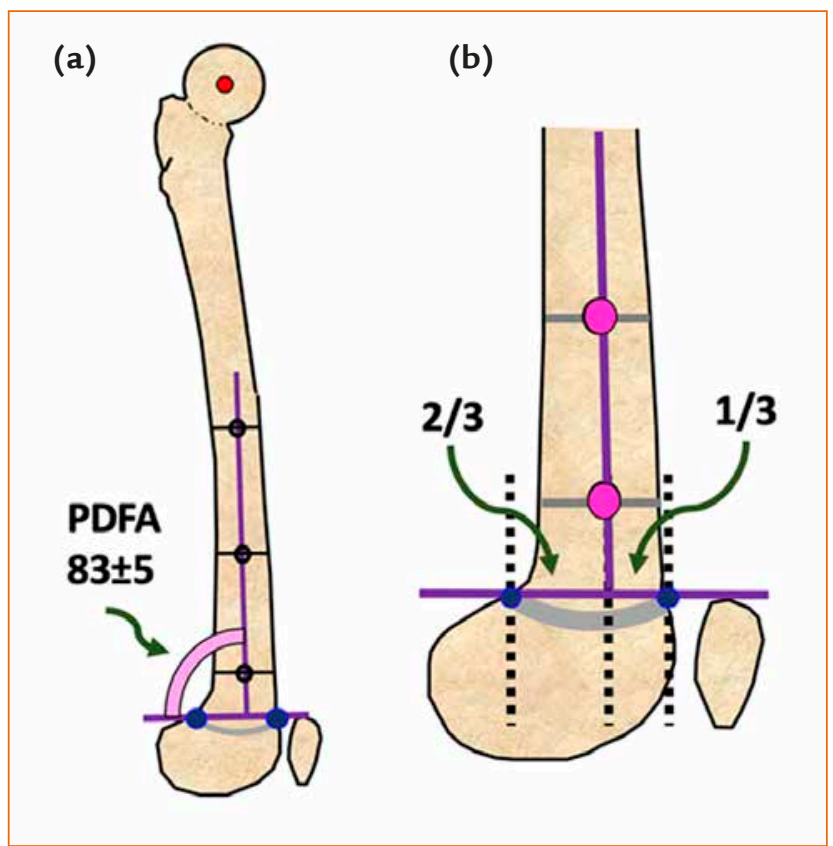

Şekil 6. a, b. aPDFA açısı; distal femur oryantasyon hattı, femur anatomik ekseni ile posteriorda ortalama $83^{\circ}$ 'lik bir açı yapar (a). Femur anatomik ekseni distal femur oryantasyon hattını $1 / 3$ anteriorda keser (b).

noktası ile Blumensaat çizgisinin 1/3 ön kısmının birleştirilmesi sonrası posteriorda oluşan açıya mPDFA (mekanik Posterior Distal Femoral Açı) adı verilir, normal değeri $83^{\circ}$ 'dir (Şekil 6). mPDFA $79^{\circ}$ 'den az ise prokurvatum, $87^{\circ}$ 'den fazla ise rekurvatum deformitesinin varlığını gösterir. Tibiada mekanik eksene göre eklem oryantasyonunun değerlendirilmesinde ise, sagittal planda proksimalde eklem oryantasyon çizgisinin $1 / 5$ anterioru ile, distal eklem çizgisinin orta noktası birleştirilir. Proksimalde posteriorda oluşan açı aPPTA olup, normal değeri $81^{\circ} \pm 4^{\circ}$ 'dir (Şekil 7). Distal anteriorda oluşan açı aADTA olup, normal sınırları $80^{\circ} \pm 2^{\circ}$ 'dir (Şekil 8 ). aPPTA değeri $77^{\circ}$ 'nin altında ise tibiada prokurvatum, $85^{\circ}$ 'nin üzerinde ise rekurvatum deformitesi mevcuttur (Şekil 2, 3).

\section{Sagittal Plan Deformitelerinde Maloryantasyon Testi}

Illk aşamada mPDFA ölçülür. Açı $79^{\circ}$ 'den az ise distal femoral prokurvatum, $87^{\circ}$ 'nin üzerinde ise distal femoral rekurvatum deformitesi mevcuttur. İkinci olarak mPPTA ölçülür. Açı $77^{\circ}$ 'den az ise distal tibial prokurvatum deformitesi, $85^{\circ}$ 'den fazla ise rekurvatum deformitesi mevcuttur.

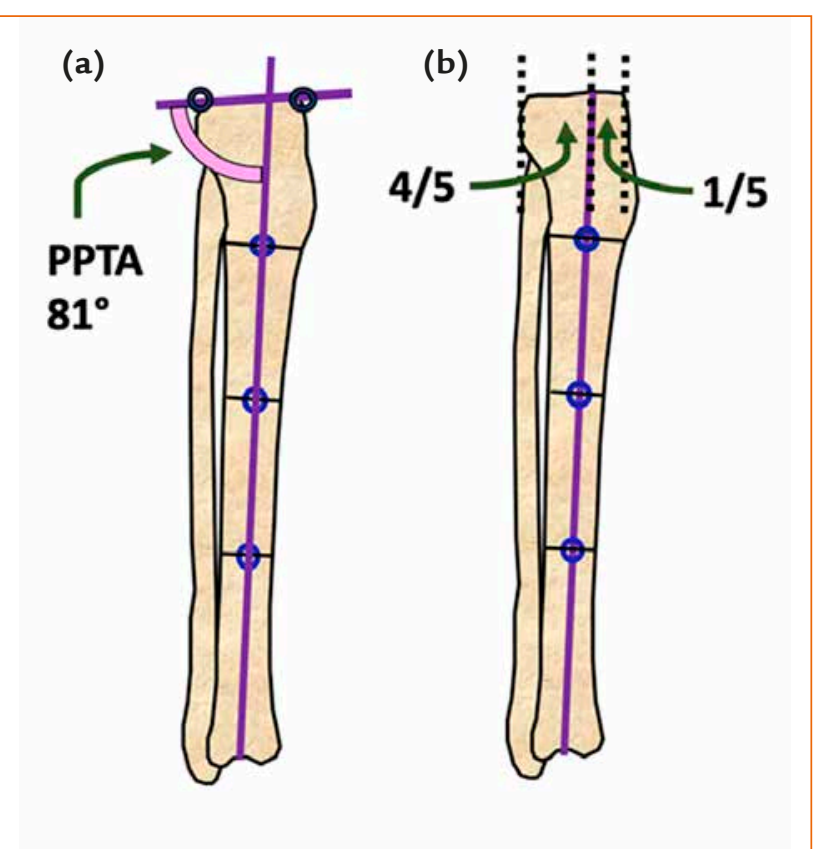

Şekil 7. a, b. Tibia anatomik ekseninin proksimal tibia eklem oryantasyon hattını kesmesi ile aPPTA açısı oluşur.

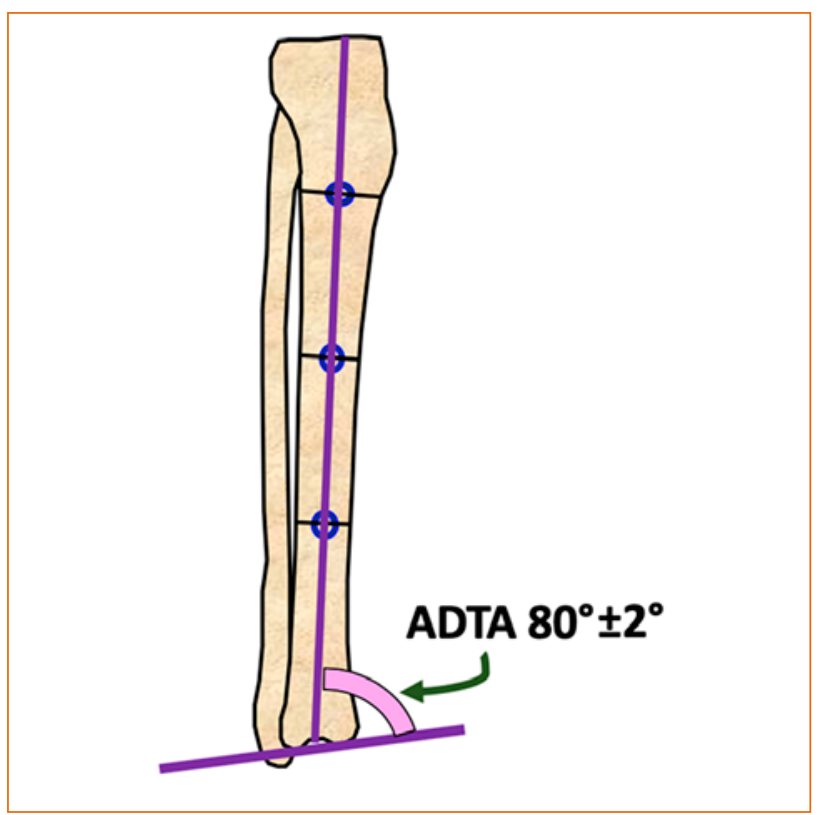

Şekil 8. aADTA açısı distal tibia oryantasyon hattı ile tibia mekanik ekseni arasındaki açıdır ve $80^{\circ}$ olup, $78^{\circ}-82^{\circ}$ arası normal sınırlarıdır.

Diz tam ekstansiyonda iken distal femurun anterior korteksinden geçen çizgi ile proksimal tibianın anterior korteksinden geçen çizgi aynı düzlemdedir. Bu iki çizginin kesişmesiyle oluşan açı $0^{\circ}$ 'den küçük ise fleksiyon kontraktürü, $5^{\circ}$ den büyük ise hiperekstansiyon kontraktürü mevcuttur. Bu ölçümler sonucunda dizde 


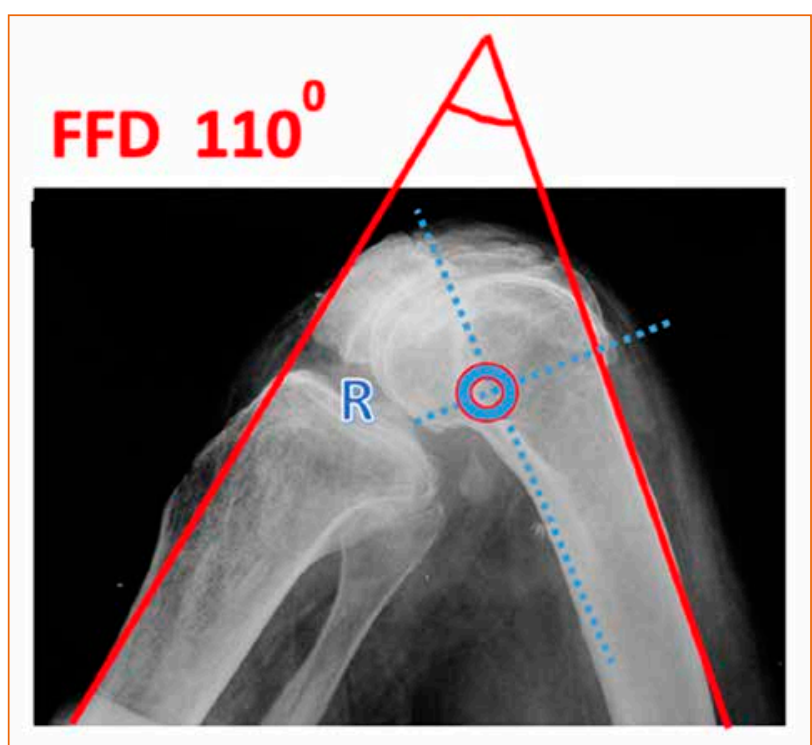

Şekil 9. Dizde fleksiyon kontraktürü olan bir hastada sagittal planda lateral diz radyografisinde kontraktürün ölçülmesi ve diz eklemi rotasyon merkezi $(R)$.

prokurvatum (fleksiyon) ya da rekurvatum (ekstansiyon) deformiteleri varlığı saptanır. Mekanik eksene göre; femoral, tibial ya da her ikisinde deformitenin birlikteliği ile diz eklem kontraktürü ve subluksasyonları saptanır (Şekil 6).

\section{Ayak Bileği Eklemi Maloryantasyon Testi}

ADTA ölçümü yapılır, $78^{\circ}$ 'den az ise distal tibial rekurvatum, $84^{\circ}$ 'den fazla ise prokurvatum deformitesi mevcuttur. Bu ölçüm ile ekstra artiküler deformiteler değerlendirilebilir.

\section{Diz Fleksiyon Kontraktürlerinde Yaklaşım}

Diz fleksiyon kontraktürleri, yürüyüş bozuklukları ile birlikte boy eşitsizliğine sebep olurlar. Diz fleksiyon kontraktürünün derecesi arttıkça daha fazla kısalık varmış görüntüsü verir. Yüksek derecelerdeki fleksiyon deformiteleri, kuadriseps adelesinin yetmezliğine sebep olur. Diz fleksiyon kontraktürü arttıkça, kuadriseps adalesi gövdeyi öne doğru dik tutmaya çalışacağı için fazla çalışır ve bunun için büyük derecelerdeki fleksiyon kontraktürleri $\left(5^{\circ}\right.$ 'nin üzerinde) semptomatiktir ve tedavi gerektirir. Diz fleksiyon kontraktürleri, cerrahi olmayan; diz manüplasyonu, fizik tedavi programları ve germe egzersizleri ile tedrici düzeltme sonrası splintleme veya alçılama yöntemleriyle tedavi edilebilir. Bu yöntemlerle tedavi edilemeyenlere, cerrahi olarak; yumuşak doku veya kemik prosedürleri uygulanır. Yumuşak doku gevşetmeleri akut veya tedrici olarak

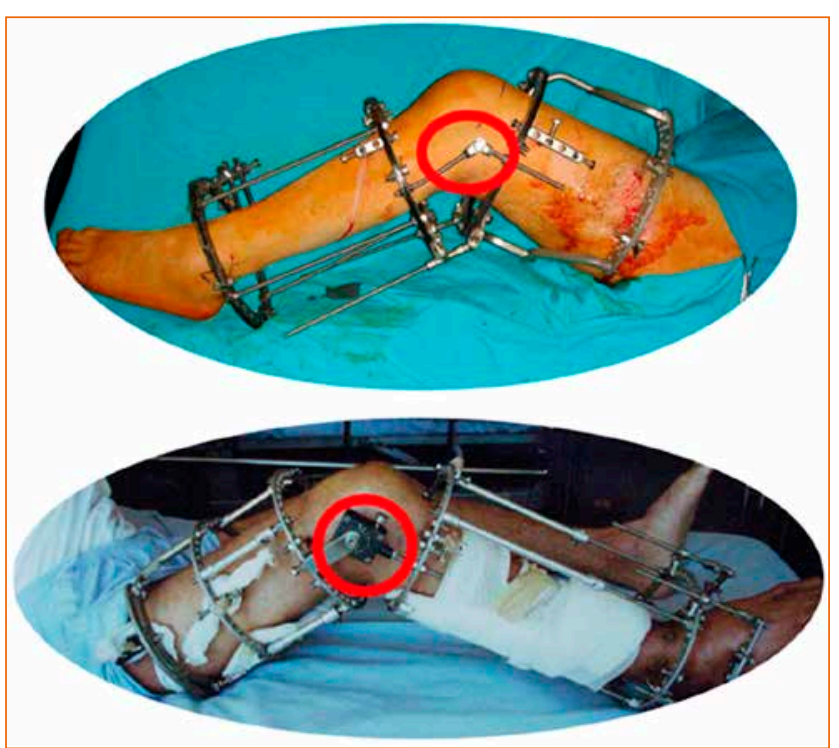

Şekil 10. Fleksiyon kontraktürü olan hastalarda illizarov tipi eksternal fiksatör yardımıyla farklı iki tip kontraktür menteşesi kullanılarak tedrici distraksiyon uygulanması.

yapılabilir. Akut düzeltmeler, Hamstring tendonlarının uzatılması ile birlikte gastroknemius adelesinin kısmi intramüsküler veya tenotomi ile tendonunun uzatılmasını, posterior kapsüler gevşetme ile birlikte arka çapraz bağın gevşetilmesini kapsar. Tedrici olarak eklemin ekstansiyona getirilmesi eksternal fiksatörler ile olur (Şekil 9, 10). Diğer cerrahi seçenekler ise; femur ve/ veya tibianın ekstansiyon osteotomisidir. Sagittal planda PDFA veya PPTA normalden daha az ise, deformitenin kemik komponentinin varlığını gösterir ve bu olgular ekstansiyon osteotomisi ile tedavi edilir. Osteotomi, gerçek kemik deformitesinin varlığında veya çok az yumuşak doku kontraktürü var olduğunda yapılmalıdır. Yumuşak doku kontraktürlerinde; yumuşak doku gevşetmeleri veya tedrici eklem distraksiyonu öncelikli tedavi yöntemi olmalıdır. Vakaların bir kısmında fleksiyon deformitesi kompleks olup, yumuşak doku ve kemik komponenti birlikte görülebilir. Femoral deformitenin tam olarak düzeltilmesi, tibial deformiteye göre daha fizyolojiktir. Femurun ekstansiyon osteotomisi ile aşırı düzeltilmesi, femur kondilini sınırlayarak fleksiyon kaybına neden olurken, tibial aşırı düzeltme fleksiyon kaybına neden olmaz, ancak tibianın posteriora açılanmasında kayıpla birlikte femurun tibia üzerinde yer değiştirme mekanizmasını bozar. Bu bakımdan tibiada PPTA $90^{\circ}$ 'den fazla düzeltilmemelidir. Kompleks diz fleksiyon kontraktürleri ve kemik deformite varlığında tüm düzeltme kemikten yapılmalıdır. Yumuşak dokudan yapılacak düzeltmeler, deformitenin tekrarlamasına sebep olur. 
Femoral prokurvatum deformitesinin tedavisinde tibial ekstansiyon osteotomisi yapılırsa diz posteriora sublukse olur. Nöromüsküler disfonksiyonu olan hastalarda oluşan fleksiyon kontraktürlerinde, kemikte prokurvatum ve tam olmayan hiperekstansiyon kompansasyonundan dolayı, prokurvatum normal açıdan $5^{\circ}$ daha az düzeltilerek tedavi edilir. Prokurvatumun tam düzeltilmesi; Hamstring adalelerinin zayıflı̆ı nedeniyle dizin hiperekstansiyonunun kontrol edilememesine sebep olur.

Diz fleksiyon kontraktürlerinde akut düzeltmeyi kısıtlayan en önemli faktör nöromusküler yapılardır. Yapılacak akut aşırı düzeltmeler nörovasküler hasarlanmaya sebep olabilir. ${ }^{[6]}$ Ameliyat öncesi (preoperatif) eklem kontraktürü yokluğunda, osteotomi sonrası yumuşak doku gevşetmeleri gerekli olabilir. Suprakondiler femoral ekstansiyon osteotomisi sonrası, Hamstring gevşetmesi gerekli olabilir.

Çocuklarda diz fleksiyon kontraktürlerinde; ekstansiyon manüplasyon veya alçılama distal femurda kıkırdak hasarı ve düzleşmeye neden olur. Kontraktür gevşetme ve eklem distraksiyonu sonrası sıklıkla rekürrens gelişir. Bu olgularda suprakondiler osteotomi ile reoryantasyon yapılmalıdır.

Osteotomi diz fleksiyon kontraktürlerinin tedavisinde tercih edilen tedavi yöntemidir. Yumuşak doku gevşetilmesi veya eklem distraksiyonu tercih edilen tedavi yöntemi olmasına karşın, nüks ve fazla miktarda skar dokusu oluşumu en önemli dezavantajlarıdır. Deformite ekstraartiküler ise; düşük derecelerde akut yüksek derecelerde tedrici düzeltme yapılmalıdır. Deformitenin angulasyon-rotasyon merkezi diz ekleminde ve subluksasyon yok ise; deformite tibia ve femurun posterior kortikal çizgileri ile değerlendirilir. Subluksasyon olan hastalarda diz fleksiyon kontraktürü en iyi eksternal fiksatörler ile düzeltilir. Menteşe, proksimale kaymış rotasyon-angulasyon merkezine yerleştirilir. Distal femoral ve proksimal tibial prokurvatum, subluksasyona sebep olur. Paralitik diz fleksiyon kontraktürü olan hastalarda (poliomyelit, spina bifida vb) diz fleksiyon kontraktürü, distal femoral ekstansiyon osteotomisi ile tedavi edilir. Bu hastalarda osteotomi sonrası düzeltme nötral ya da $5^{\circ}$ fazla yapılır, bu da dizin güçlenmesine olanak sağlar.

\section{Diz Hiperekstansiyon ve Rekurvatum Deformitesi}

Rekurvatum deformitesi dizde genellikle asemptomatiktir. Dizin maksimum ekstansiyonunda sağlıklı kişilerde; adele gücü ve propriyosepsiyon, kemik ve kapsüloligamentöz engelleme gücüne göre daha belirgindir. Normal yürüme esnasında diz ekstansiyonu, tam ekstansiyon değerinden $3^{\circ}-5^{\circ}$ daha düşüktür. Kapsül ve arka çapraz bağ hiperekstansiyonu engelleyemez. Hiperekstansiyonda hamstring adele fonksiyonları önemlidir.

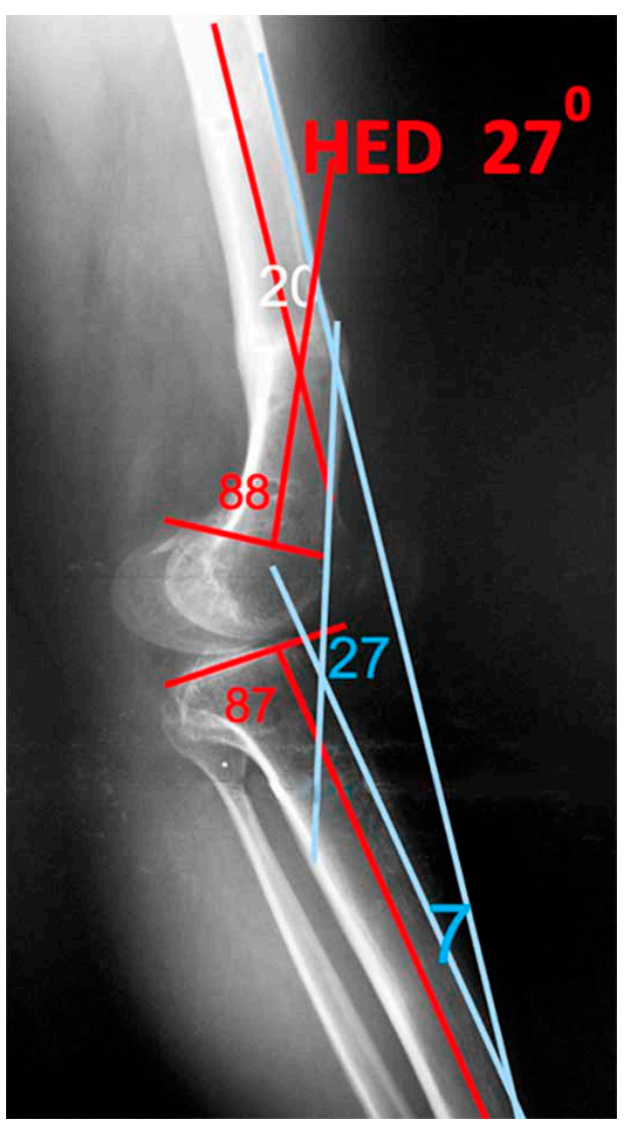

Şekil 11. Dizde hiperekstansiyon kontraktürü olan bir hastanın radyografik olarak sagittal planda kontraktürünün değerlendirilmesi.

Hiperekstansiyon yumuşak doku ve/veya kemik kökenli olabilir. PPTA veya PDFA $85^{\circ}-87^{\circ}$ 'den daha büyük ise; tibia veya femurda rekurvatum deformitesi mevcuttur. Femoral deformite sonrası gelişen rekurvatum, tibial rekurvatumdan farklıdır. Femoral rekurvasyonda diz hareket açıklığında kayıp olur, fakat diz fleksiyonu etkilenmez. Tibial rekurvasyonda ise; diz posteriora sublukse gibi görülür, ancak tibianın femura göre ön tarafa doğru çökmesi mevcuttur (Şekil 11). Klinik olarak femoral prokurvatum normal, ancak tibial rekurvatum semptomatiktir. Femoral rekurvatum sonucu tibianın anterior yüzeyinde kıkırdak hasarı sonrası posterior tibial subluksasyon, patella baja, kondromalazi ve tibiofemoral-patellofemoral eklemde dejenerasyon gelişir. ${ }^{[7]}$

Hiperekstansiyon deformitesi distal femoral veya proksimal tibial prokurvatum sonrası gelişmiş ise; hiperekstansiyon kontraktürünün derecesi kadar osteotomi ile düzeltilebilir, ancak aşırı düzeltme fleksiyon kontraktürü ile sonuçlanır. Hiperekstansiyon 
deformitesi kemik deformitesinden biraz fazla ise; osteotomi ile düzeltilebilir. Nöromüsküler olarak sağlıklı kişilerde rezidüel yumuşak doku kontraktürleri klinik olarak sorun yaratmaz. Nöromüsküler disfonksiyonu olan hastalarda hamstring fonksiyonlarının yetersizliğinde, eklem laksitesi yoksa fleksiyonda aşırı düzeltme yapılmalıdır. Fleksiyon osteotomisi, ayak-ayak bileği ortezi kullanımı gastroknemius adelesinin fleksiyon yeteneğini artırır. Tibial rekurvasyon deformitesi, femoral fleksiyon osteotomisi ile düzeltilemez. Bu dizde posterior subluksasyona neden olur. Femoral rekurvasyon tibial fleksiyon osteotomisi ile düzeltilemez, anterior diz subluksasyonu gelişir. Tibianın rekurvasyon deformitesi, patellar tendon insersiosu düzeyinde osteotomi ile düzeltilebilir, bu tedavi patella baja gelişimini engeller. Açık kama osteotomisi, patellar tendonu normal şekline doğru yönlendirerek; dolaylı olarak rekurvasyonu düzeltir ve bununla birlikte fibulayı distale çekerek, dış yan bağ ( $L C L$ ) yoluyla dizin redüksiyonuna katkıda bulunur. Fleksiyon kontraktürü ile birlikte prokurvatum ve subluksasyon varsa; osteotomi tuberositas tibianın proksimalinden yapılmalıdır.

\section{Diz Ekstansiyon Kontraktürü}

Diz ekstansiyon kontraktürü konjenital veya edinsel kökenli olabilir. Tedavi edilmeyen olgularda, distal femoral büyüme rekurvatuma doğru gider. Erken dönemde tedavide alçılama ya da cerrahi tedavi uygulanır. Kazanılmış ekstansiyon kontraktürü genellikle posttravmatik ya da diz cerrahisine sekonder gelişir. Dizdeki sertlik artrogripozisteki gibi parsiyel veya total olabilir. Artrogripozis tüm dizi tutabilir veya daha belirgin olarak patellofemoral çıkıntı tutulur, intraartiküler yapışıklıklar ve kapsüler kontraktürler diz eklemi fleksiyonunu sınırlar. Dizi uzun süre ekstansiyon pozisyonunda tespit edilen hastalarda, kuadriseps kontraktürüne bağlı ekstansiyonda sertlik gelişir. Kuadrisepste skar oluşumu, önce geçirilen cerrahi ve travmayla ilişkilidir. Kuadriseps adalesindeki skar kemiğe doğru uzanarak fasyal yapıları çevreler. Fasyal yapıların etrafı çevrelemesiyle dizde ekstansiyon kontraktürü meydana gelir. Fasya lata ve uyluğun anterior fasyası oldukça kalın ve kontraktedir. Rektus femoris kası ve tendon kontraktürleri diz fleksiyonunu özellikle proje pozisyonda sınırlar. Kuadriseps adelesinin yalnızca bir kısmı kalça ekleminden başladığından, rektus femoris kontrakte ise Ely testi pozitif olur. İç yan bağ (MCL), dizin uzun sürekli tam ekstansiyonu ile kontrakte olur. MCL'nin lifleri normalde diz $60^{\circ}$ fleksiyonda iken en uzun şekle sahiptir, diz tam ekstansiyonda iken kontrakte olarak diz fleksiyonunu kısıtlar. Patolojik değişiklikler sonrası intraartiküler yapışıklıklar total artrofibrozise gidişe neden olur.
Kapsüler kontraktür, kuadriseps kontraktürü, kemik adhezyonlar, fasyal kontraktürler ve MCL kontraktürü birlikte diz fleksiyonunu sınırlar.

Diz ekstansiyon kontraktürünün tedavisi çok değişiklik göstermektedir. Artroskopi ile eklem içi adhezyonların gevşetilmesinden, agresif kuadrisepslastiye kadar geniş tedavi seçenekleri mevcuttur. Kuadrisepsplasti; proksimal ve distal bazlı yapılabilir. Distal kuadrisepsplasti; Thompson veya V-Y tipi yetişkinlerde yapıldığında, dizde ekstansiyon kaybına yol açabilir, çocuklarda tercih edilmelidir. Tercih edilen yöntem erişkinlerde Judet kuadrisepsplastisidir. ${ }^{[8]}$ Bu proksimal bazlı quadrisepsplasti olup, kuadriseps adalesinin tüm elementlerini kapsar. Bu yöntem Letournel tarafından popülarize edilmiştir. ${ }^{[9]}$ Judet kuadrisepsplastisi aşamalı olarak yapılan bir gevşetme yöntemidir. İntraartiküler olarak yapışıklıklar gevşetilir, MCL ve medial kapsüler gevşetme yapılır, anterior superior ilyak çıkıntıdan rectus femoris gevşetilir, fasya lata ve uyluk anterior fasyasına kısmi uzatma yapılarak diz ekleminde maksimum fleksiyon hedeflenir. Insizyon standart olarak lateral yüzden lineer ve "S" şeklinde yapılır ancak aynı seansta diz artroplastisi yapılacaksa anterior yaklaşım tercih edilir.

\section{Ayak ve Ayak Bileği Sagittal Plan Deformiteleri}

Distal tibia deformitelerini değerlendirmede talus, kalkaneus ve ayağın pozisyonu oldukça önemlidir. Talus, frontal planda kare şeklinde çapraz kesitsel görünüme sahiptir. Talusun superior dome tibial plafonda paraleldir. Normalde talar dome ile tibial plafond arasında konverjans yoktur, lateral ve medial kortikal çizgiler talusu lateral ve medialde keser. Sagittal planda tibianın diafizinin ortasından geçen çizgi, talusun lateral çıkıntısından geçer. Burası ayak bileği rotasyon merkezidir. Ayak ve tibia arasındaki açı $90^{\circ}$ olduğunda tibia plafondu arkaya doğru tilt yapmıştır $\left(\right.$ aADTA $\left.=80^{\circ}\right)$ (Şekil 8). Sagittal planda talusun eklem yüzeyi sirkülerdir ve üç boyutlu cone şeklindedir. Bu yüzden ayak bileği rotasyon ekseni eklem çizgisine paralel değildir, medial malleolun uç noktasından lateral malleol ucuna uzanır ve talusun lateral çıkıntısından geçer. Kalkaneus oryantasyonu, rölatif olarak talus ve tibiaya göre daha önemlidir. Sagittal planda kalkaneus gövdesinin uzun ekseninde inklinasyon vardır. Frontal planda kalkaneus uzun eksenini radyografi olarak görüntülemek güçtür. Klinik olarak en iyi posteriordan değerlendirilebilir. Frontal planda kalkaneus gövdesi, tibianın anatomik eksenine paraleldir, kalkaneus uzun eksenini görüntülemek için; uzun aksiyel grafi $45^{\circ}$ veya $20^{\circ}$ horizontal inklinasyonla çekilir (Saltzman grafisi) ve ayak bileği eklem oryantasyonu değerlendirilir. Tek 
ayak stance fazı esnasında yer reaksiyon kuvvetlerinin vektörü ayak bileği ve subtalar eklem lateralinden geçer ve bu eklemler valgus yüklenmesine maruz kalır. Sagittal planda, yer reaksiyon güçlerinin vektörü rotasyon merkezinin anteriorundan geçer.

Ayak bileği plantar ve dorsifleksiyonu, distal tibianın prokurvatum ve rekurvatum deformiteleri ile kompanse edilir. Ayak bileği eklemi normalde $20^{\circ}$ dorsifleksiyon ve $50^{\circ}$ plantar fleksiyon yapabilir. Bu yüzden ayak bileğinde rekurvatum, prokurvatuma göre daha iyi kompanse edilebilir. Tibia distalinde rekurvatum deformitesi, prokurvatuma göre daha iyi tolere edilir. Kompanse edilemeyen prokurvatum deformitesi ile birlikte ekin deformitesi gelişir. Bu hastalar sadece semptomatik olmayıp, ekin deformitesi nedeniyle tibia anterioru ve talus boynu arasında impingement vardır. Kompanse prokurvatum deformitesinde; sıkışma ve dorsifleksiyon kısıtlılığı vardır, merdiven inip-çıkmada semptomatik hale gelir. Prokurvatum deformitesinde distal tibia deplase olur ve ayak bileği rotasyon merkezi posteriora yer değiştirir. Distal tibia rekurvatum deformitesi genellikle başlangıçta asemptomatiktir. Plantar fleksiyon açıklığının fazla olması nedeniyle kolay tolere edilir. Ayak bileği rotasyon merkezi anteriora doğru yer değiştirir. Yürüyüşün stance fazında uzama olur ve koşma yeteneğini etkiler çünkü plantar fleksiyon gücü zayıflar. Rekurvatum deformitesinde, talusla temas eden yüzey oldukça azalır; eklemde yüklenmeyi ve dejenerasyona gidişi hızlandırır.

Distal tibiadaki tüm açısal deformiteler dejenerasyonu hızlandırır. Rekurvatumda talus yeterince kaplanamaz; ayak öne doğru giderken, yük binen kısım arkaya doğru kayar. Rekurvatumla birlikte yer reaksiyon kuvvetlerinin vektörü anteriora doğru yer değiştirir ve bu süreç dejeneratif artrit oluşumunu hızlandırır. Rekurvatum deformitesinde fleksiyon osteotomisi dejeneratif değişikleri engeller ve tedavi eder. Açık kama ostetomisi, kapalı kama osteotomisi veya dome osteotomi yapılabilir.

\section{Rekurvatum ve Prokurvatum Deformitesinde Supramalleoler Osteotomi}

Sagittal plan deformitesinde rotasyon merkezi genellikle deformitenin distalindedir, bu yüzden rekurvatum düzeltmelerinde anterior translasyon ve prokurvatum düzeltmelerinde posterior translasyon olur. Rekurvatum düzeltilmesinde bu translasyon yaptırılmazsa, ayak posteriora deplase olur, prokurvasyon düzeltmelerinde ise anteriora deplase olur. Anterior translasyon deformitelerinde ayağın kaldıraç kolu artar ve orta düzeyde sert ayak gelişir. Ayak tabanında aşırı yüklenmeye karşın, ön ayakta daha az yüklenme görülür. Translasyon miktarı deformitenin rotasyonangulasyon merkezinin, osteotomiye uzaklığına bağlıdır. Ayak bileği artrodezi ve düz tepe (flat-top) talus durumunda gelişen ekin deformitesinin rotasyon-angulasyon merkezi tibiada değildir, genellikle ayak bileği rotasyon merkezindedir. Bu ekin deformitesi genellikle sert ayak bileği ile karekterizedir; deformite ancak osteotomi ile düzeltilebilir. Osteotomi seçenekleri; supramalleoler, talar, talokalkaneal ya da orta-ön ayak osteotomileri olabilir. ${ }^{[10-12]}$

Supramalleoler osteotomi iyi bir seçenektir; ekin deformitesinin akut düzeltilmesinde kullanılır, ancak akut düzeltmede posterior translasyon nedeniyle Tarsal tünelde sıkışma olabilir ve bu olgularda proflaktik Tarsal tünel gevşetmesi gereklidir. Tedrici düzeltme ileri derecedeki deformitelerde uygulanır, Tarsal tünel gevşetmesine gerek duyulmaz.

Ayak bileği artrodez deformitelerinde genellikle frontal planda angulasyon mevcuttur. Bu olgularda sagittal planda rotasyon-angulasyon merkezi osteotominin distalinde iken, frontal planda osteotomi seviyesinde olduğu için oblik plan deformitesi olarak düzeltilmelidir.

Hafif ve orta düzeydeki ayak bileği deformitelerinin çoğu, ayak mobil olduğu için çok iyi tolere edilir. Bunun sebebi; kalça, diz, ayak bileği ve kalça ekleminin birlikte hareket edebilmesidir. Normal eklem hareketleriyle birçok deformite için; eklem hareket açıklığı ve açısal deformitenin büyüklüğü ile ilişkili olmak üzere kompansasyon mevcuttur. Tibiotalar deformitelerde, subtalar eklem kompansasyonu, tibiaya göre ayakta translasyon deformitesi oluşturur. ${ }^{[13]}$ Subtalar eklem ve deformite ekseni, tibiotalar eklemden farklıdır. Bu zig-zag deformitede subtalar eklemin kompansasyonu olup, valgus deformitesi ile sonuçlanır; semptomatiktir ve estetik olarak kötü görünümdedir. Zamanla dejeneratif değişiklikler gelişir, eklem kontraktürü ve subluksasyon olur. ${ }^{[14]}$ Distal tibia valgus deformitesinde kompansasyon subtalar inversiyon ile olur. Distal tibia rekurvatum deformitesinde ise; ayak bileği plantar fleksiyonu ile kompanse edilir. Her iki deformitede rekurvatum anteriora translasyon ile kompanse edilir. Translasyon nedeniyle kompanse edilen eklemin rotasyon merkezi, distal tibiada açısal deformitenin rotasyon-angulasyon merkezinin distalindedir. Translasyon deformitesi benzer büyüklükte ancak farklı yönde iki angulasyonla sonuçlanır (zig zag deformitesi). Bu deformite ayakta yük binen alanı azaltarak, ayak bileğinde subluksasyon ve dejeneratif değişikliklere yol açar.

Distal tibia anguler deformitelerinde kompansasyon olarak kontraktür gelişir, kompanse edilen eklemde 
hareket kısıtlılığı oluşur. Bu durumda sadece ayak bileğinde sertliğin giderilmesi yeterli olmayıp, beraberinde primer deformitenin de düzeltilmesi gereklidir. Primer deformiteye osteotomi yapılmadan önce kompansatuvar eklemin kontraktürü ayrıntılı olarak değerlendirilmelidir. Ayaktaki angulasyon, rölatif olarak tibial deformitenin açısal büyüklüğüne eşit veya daha fazla ise sabit kompansasyon yoktur. Ayaktaki angulasyon, distal tibia deformitesinin açısal büyüklüğünden daha düşük ise kompansatuvar eklemde sabit kontraktür gelişmiştir.

Deformite tamamen kompanse, hasta semptomatik ve kabul edilebilir estetik görünüm varsa; hastaya tabanlık, ortez ve özel yapım ayakkabılar gibi cerrahi dışı tedavi yöntemleri önerilebilir. Cerrahi tedavinin tek endikasyonu uygun vakalarda geç dejeneratif artrit gelişimini önlemektir. Eğer hasta semptomatik, kompansatuvar deformite pasif olarak kısmen düzeltilebiliyorsa; deformitenin kısmi olarak korreksiyonu supramalleoler osteotomi ile yapılabilir. Kısmi deformite düzeltilmesi, kompansatuvar hareket açıklığının düzeltilebilirliği kadar olmalıdır.

Diz ayağın pozisyonundan etkilenirken aynı şekilde ayağın pozisyonu da dizin dizilimini etkiler. Dizin hiperekstansiyon deformitesi, ayağın ekin deformitesiyle kompanse edilir ve geç dönemde dizde sorun oluşturur. Ekin deformitesi düzeltildikten sonra diz fleksörleri sağlıklı çalışıyorsa hiperekstansiyon deformitesi kalıcı bir sorun oluşturmaz. Hastada diz fleksörleri yeterince çalışmıyorsa veya poliomyelit gibi hastalıklarda; ekin deformitesinin düzeltilmesi sonrası dizdeki hiperekstansiyon kontrol edilemez.

Diz fleksiyonu kalkaneal deformite ile kompanse edilir. Bu durumda dizin sabit fleksiyon deformitesi varlığında kalkaneal deformite düzeltilmez. Ayak bileği füzyonuna bağlı lateral planda sıklıkla ekin deformitesi görülür. Osteotomi; yalnızca frontal plandaki rotasyon-angulasyon merkezine göre yapılırsa yalnızca angulasyon, sagittal plana göre yapılırsa angulasyon ve posterior translasyon düzeltilir.

Düz tepe talus deformitesi genellikle pes ekinovarus tedavisinin geç sekelidir. Ayak bileğinin aşırı dorsifleksiyona zorlanmasıyla talusun kıkırdak çatısı ekin pozisyonunda düzleşir, ayak bileği sertleşir ve hareket açıklığı azalır. Supramalleoler osteotomi ile düzeltme olabildiğince distalden yapılırsa, posterior translasyon en aza indirgenebilir. Akut düzeltme yapılacak vakalarda, proflaktik Tarsal tünel gevşetmesi yapılmalıdır. Ayrıca düz tepe talusta "U" ve "V" osteotomiler yapılabilir. "U" osteotomi ile tibia ve ayağın pozisyonu düzeltilebilir, fakat "V" osteotomi ile çiftli osteotomi sonrası ön ve orta ayak düzeltilebilir. Daha fazla düzeltme gereksinimi olduğunda supramalleoler osteotomi ile kombine edilebilir. Alternatif bir yöntemde; üçlü subtalar-orta ayak füzyonu ile birlikte deformitenin düzeltilmesi yöntemidir, ancak kısa ve sert bir ayak oluşur.

\section{Ayak Bileği Kontraktürleri}

Ayak bileği kontraktürleri; intraartiküler, ekstraartiküler veya kombine olabilir. Eklem dışı kontraktürler Aşil tendonu, triseps surae, tibialis posterior, fleksör hallusis longus ve fleksör digitorum longus adelesi ile ilişkilidir. Silverskiöld testi ile, diz fleksiyonda iken ekin deformitesi düzeliyorsa; kontraktür gastroknemius kökenli olup, gevşetme gastroknemius adelesinden yapılır. Diz fleksiyonda iken düzelme olmuyorsa kontraktür gastro-soleus veya intraartikülerdir. Klinik bulgular ayırıcı tanıda yardımcı olur. Konjenital ekin deformitelerinde genellikle fasyal ve kapsüler komponent vardır. Bu olgularda Aşil tendonu perkütan ya da Z-plasti ile uzatılabilir. Aşiloplasti ile tam düzelme sağlanamayan olgularda ilave yumuşak doku gevşetmesi ya da eksternal fiksatör ile tedrici düzeltme sağlanabilir. Akut yumuşak doku gevşetmesinde posterior derin fasya, kapsül ve gerekirse intraartiküler yapışıklıklar serbestleştirilebilir. Kemiksel sıkışma varsa; talus dorsal oyuğu veya tibianın anterior kısmındaki osteofitler rezeke edilir, böylece talusun dorsifleksiyonu rahatlatılır. Radikal yumuşak doku gevşetmesi ile tedrici distraksiyon, şiddetli ekin kontraktürlerinde (geçirilmiş çok sayıda operasyon, artrogripozis vb.) seçkin tedavi yöntemidir. Hafif derecedeki ekin kontraktürlerinde menteşeli ayak bileği çerçeveleri kullanılarak yapılan düzeltmelerde ayak bileği eklemine bir miktar distraksiyon uygulanır. Menteşeler ayak bileği rotasyon eksenine uygun yerleştirilir. Bu işlem Ilizarov tipi eksternal fiksatörler ile yapılabilir. ${ }^{[15]}$ Tedrici distraksiyonun en büyük avantajı nörovasküler yaralanma riskini azaltmasıdır. Varus ve ekin deformitesi birlikteliğinde, önce varus sonra ekin deformitesi düzeltilmelidir.

\section{KAYNAKLAR}

1. Tetsworth K, Paley D. Malalignment and degenerative arthropathy. Orthop Clin North Am 1994;25(3):367-77.

2. Perry J, Brunfield JM. Gait Analysis: Normal and Pathological Function, 2nd ed. New Jersey: Slack Inc.; 2010.

3. Paley D, Tetsworth KT. Mechanical axis deviation of the lower limbs: Pre-operative planning of uniapical angular deformities of the tibia or femur. Clin Orthop Relat Res 1992;(280):4864. Crossref

4. Wright JG, Treble N, Feinstein AR. Measurement of lower limb alignment using long radiographs. J Bone Joint Surg $\mathrm{Br}$ 1991;73-B(5):721-3. Crossref

5. Paley D, Tetsworth KT. Deformity correction by the Ilizarov technique. In: Chapman MW, editor. Operative Orthopaedics, 2nd ed. Philadelphia, Pa: JB Lippincott Co; 1993. pp.883-948. 
6. Herzenberg JE, Davis JR, Paley D, Bhave A. Mechanical distraction treatment of severe knee flexion contracturs. Clin Orhop Relat Res 1994;(301):80-8. Crossref

7. Bowen JR, Marley DC, Mc Inery V, MacEven GD. Treatment of genu recurvatum by proximal tibial closing wedge/ anterior displacement osteotomy. Clin Orthop Relat Res 1983;179(1):194-9. Crossref

8. Ebraheim NA, DeTroye RJ, Saddemi SR. Results of Judet kuadrisepsplasty. J Orthop Trauma 1993;7(4):327-30. Crossref

9. Merchan EC, Myong C. Qudricepsplasty: the Judet rechnique and results of 21 postraumatic cases. Orthopaedics 1992;15(9):1081-5.

10. Paley D. The correction of complex foot deformities using Ilizarov's distraction osteotomies. Clin Orthop Relat Res 1993;(293):97-111. Crossref

11. Paley D. Principles of foot deformity correction: Ilizarov technique. In: Gould JS, editor. Operative Foot Surgery. Philadelphia: WB Saunders; 1994. pp.476-514.
12. Paley D, Herzenberg JE. Application of external fixation to foot and ankle reconstruction. In: Myerson MS, editor. Foot and Ankle Disorders, vol 2. Toronto: WB Saunders; 1999. pp.1135-88.

13. Stiehl JB. Biomechanics of the ankle joint. In: Still JB, editor. Inman's Joints of the Ankle, 2 nd ed. Baltimore (MD): Williams and Wilkins; 1991. pp.39-63.

14. Puno RM, Vaughan JJ, Stetten ML, Johnson JR. Long-term effects of tibial angular malunion on the knee and ankle joints. J Orthop Trauma 1991;5(3):247-54. Crossref

15. Volkov MV, Ogenesyan OV. Functional restoration of joint deformities with the aid of hinged distraction apparat uses in clinical practice. In: Volkov MV, Oganesya OV editors; Burov M, transl. External Fixation: Joint Deformities and Bone Fractures. Madison, Conn.: International Universities Press; 1987. pp.151-226. 